\title{
La situación del menor en el ámbito sanitario
}

\author{
J. Ruiz Jiménez \\ Profesora de Derecho Civil de la Universidad Nacional de Educación a Distancia (UNED). \\ Especialista en Derecho Sanitario.
}

Fecha de publicación en Internet: 18 de abril de 2011

\section{Resumen}

La situación actual del menor de edad en el ámbito sanitario ha experimentado un cambio paralelo a la evolución social. Este cambio gira en torno a la autonomía de la persona, se ha pasado de una política de dependencia y sometimiento a la voluntad de los progenitores a intentar fomentar la autonomía del menor. Autonomía que se sustenta en la idea de que el menor va adquiriendo un desarrollo gradual y progresivo en su capacidad de hacer y entender.

En principio, promover la autonomía de las personas en general y de los menores en particular les lleva a tener una mayor independencia y libertad. Sin embargo, se puede general algún conflicto. En primer lugar, porque no existe un criterio claro para determinar el grado de madurez de un menor de edad para saber si es apto en la toma de decisiones cuando estamos ante un acto médico, ya que la normativa no establece ni los criterios que podrían utilizarse -tarea difícil-, ni quiénes deberían ser los profesionales para su valoración, y cuando se hace referencia al grado de madurez se hace de forma general. Y en segundo lugar porque la minoría de edad es una etapa larga en la que el menor pasa por varias fases totalmente diferentes. Aunque se ha producido un gran avance en la materia, es preciso concretar y armonizar el ordenamiento para llegar a soluciones más equilibradas.

Palabras clave: Menor. Menor maduro. Legislación.

The minor's situation in health care

\section{Abstract}

The current situation of the minor in the sanitary field has experienced a change which is parallel to the social evolution. This change spins around the person's autonomy. There has been a shift from policies of dependence and submission to the parents' will to promoting the minor's autonomy. This autonomy is supported in the idea that the minor is progressively getting a development in his/her ability to do and to understand.

As a start, promoting people's autonomy in general and minors' in particular provides them with a bigger independence and freedom. But this could generate some conflicts. In the first place, because there isn't a clear criterion to determine the maturity rate of a minor to know if he/she is able to take decisions on a medical situation. The legislation doesn't establish the criteria to be used (difficult task), neither the professionals who should make the evaluation, and when there is a reference to the maturity rate it is made in a general way. In the second place the minority is a long period in which the minor goes through very different stages. Even though a great progress in the issue has been made, it is mandatory to set and harmonize the legal code to reach to more well-balanced solutions.

Key words: Minor. Mature minor. Legislation.

Juana Ruiz Jiménez, jrjimenez@der.uned.es

La autora declara no presentar conflictos de intereses en relación con la preparación y publicación de este artículo. 


\section{Introducción}

La minoría de edad es una etapa en la vida de una persona relativamente amplia, comparada con otras especies, y en la que existe una gran dependencia. En el ámbito jurídico-civil, es de vital trascendencia la demarcación de esta fase de la vida, pues la separación entre minoría y mayoría de edad supone pasar de un periodo de tu vida en el que no tienes autonomía o facultad para tomar decisiones sobre tu propia persona -minoría de edad- a tenerlas cuando llegas a la mayoría de edad. El arribo a la mayoría de edad habilita a la persona a que tenga plena capacidad y autonomía, y pueda realizar todos los actos de la vida sin intervención de terceras personas, ya sean padres o tutores. Atendiendo al momento histórico y social, ese instante en el que se adquiere la independencia ha sido cambiante, considerando que la sumisión a los padres o, mejor dicho, al padre debía llegar hasta la edad de 25 años en algunos momentos, hasta su descenso a 18 años, que es lo establecido en la actualidad en la Constitución Española. La evolución de la sociedad ha supuesto un cambio de pensamiento en relación con la persona, primando hoy la idea de autonomía y libertad del ser humano. La dificultad estriba en delimitar cuándo realmente el ser humano está capacitado para actuar de manera independiente.

Con carácter general, el tema de la adquisición de la capacidad está regulado en el Código Civil (CC). La plena capacidad de obrar se adquiere cuando se llega a la mayoría de edad, es decir, cuando se cumplen 18 años. Es preciso señalar que, con independencia de lo establecido en el Código Civil, existe un número importante de disposiciones que regulan aspectos concretos sobre la capacidad de los menores y su adquisición, y sobre ello haremos indicaciones posteriores. Pero volviendo a la capacidad en general, nos debemos hacer la siguiente pregunta: hasta que no se llega a la mayoría de edad, ¿se considera que el menor no puede tomar decisiones sobre su persona y tiene que estar sometido a lo que decidan sus padres o tutores? La respuesta podría ser positiva o negativa $y$, en ambos casos, con un sinfín de matizaciones.

Efectivamente, la respuesta podría ser positiva porque la mayoría de edad marca el comienzo legal de la plena autonomía en cualquier aspecto de la vida, sin necesidad de que el consentimiento tenga que ir complementado; sin embargo, esta respuesta habría que matizarla. Desde el punto de vista civil, los legisladores han considerado que, par- 
tiendo de la premisa de que la plena capacidad de obrar se adquiere cuando se llega a la mayoría de edad, es preciso fomentar la autonomía de la persona, en la creencia de que es la mejor manera de proteger a la persona en general y al menor en particular. Por lo tanto, no debe considerarse que la persona adquiere de un día para otro la capacidad y hasta entonces no puede valerse por sí misma, sino que esta adquisición va en paralelo con la autonomía, con el desarrollo de la capacidad natural, y a medida que la capacidad natural se va desarrollando el sujeto debe tener mayor autonomía. Las reformas legislativas ${ }^{\mathrm{a}}$ que se han producido en torno a este tema han ido orientadas en esa línea, de tal forma que dentro de la minoría de edad se tiene en cuenta al menor en numerosos supuestos y se le permite hacer determinados actos por sí solo, además de tener en cuenta su opinión para otros tantos asuntos. Por citar algún ejemplo, podríamos señalar los actos en los cuales la ley obliga a que el menor preste su consentimiento para que esos actos o contratos tengan plena validez. Se requiere el consentimiento

\footnotetext{
a Ley 11/1981, de 13 de mayo, de modificación de la filiación, patria potestad y régimen económico del matrimonio; Ley 13/1983, de 24 de octubre, en materia de tutela; Ley 21/1987, de 11 de noviembre, en materia de adopción.
}

del menor cuando los padres pretendan celebrar contratos en los que tengan que realizar prestaciones personales (art. 162.2 CC). También se requiere su consentimiento para poder ser adoptado cuando el menor es mayor de 12 años (art. 177 CC). Asimismo, será necesario el consentimiento del menor de 12 años para llevar a cabo el acogimiento (art. 173.2 CC). Puede realizar por sí mismo los actos relativos a derechos de la personalidad, esto es lo que dice el Código Civil, pero si acudimos al art. 3 de la Ley Orgánica $1 / 1982^{b}$, nos expresa que el consentimiento de los menores se presentará por ellos mismos si sus condiciones de madurez lo permiten. $Y$ a continuación establece que si no presentan esas condiciones, lo harán sus representantes legales.

De todo ello, se puede deducir que el objetivo del legislador ha sido ampliar el campo de autonomía de los menores, objetivo que halló su máxima manifestación en la Ley 1/1996 de 15 de enero de Protección Jurídica del Menor, de modificación parcial del Código Civil y de la ley de Enjuiciamiento Civil ${ }^{\mathrm{C}}$ cuya Exposición de Motivos es clara y contundente, reflejando por un lado la evo-

\footnotetext{
b Ley Orgánica de Protección Civil del Derecho al Honor, a la Intimidad Personal y a la Propia Imagen.

${ }^{C}$ BOE n. ${ }^{\circ} 15$, de 17 de enero.
} 
lución social y por otro la situación del menor tras la misma, cuando señala en su apartado segundo que:

"La presente Ley pretende ser la primera respuesta a estas demandas, abordando una reforma en profundidad de las tradicionales instituciones de protección del menor reguladas en el Código Civil.

En este sentido -y aunque el núcleo central de la Ley lo constituye, como no podía ser de otra forma, la modificación de los correspondientes preceptos del citado Código-, su contenido trasciende los límites de este para construir un amplio marco jurídico de protección que vincula a todos los Poderes Públicos, a las instituciones específicamente relacionadas con los menores, a los padres y familiares y a los ciudadanos en general.

Las transformaciones sociales y culturales operadas en nuestra sociedad han provocado un cambio en el estatus social del niño y como consecuencia de ello se ha dado un nuevo enfoque a la construcción del edificio de los derechos humanos de la infancia.

Este enfoque reformula la estructura del derecho a la protección de la infancia vigente en España y en la mayoría de los países desarrollados desde finales del siglo $x x, y$ consiste fundamentalmente en el reconocimiento pleno de la titularidad de derechos en los menores de edad y de una capacidad progresiva para ejercerlos.

El desarrollo legislativo postconstitucional refleja esta tendencia, introduciendo la condición de sujeto de derechos a las personas menores de edad. Así, el concepto «ser escuchado si tuviere suficiente juicio» se ha ido trasladando a todo el ordenamiento jurídico en todas aquellas cuestiones que le afectan. Este concepto introduce la dimensión del desarrollo evolutivo en el ejercicio directo de sus derechos.

Las limitaciones que pudieran derivarse del hecho evolutivo deben interpretarse de forma restrictiva. Más aún, esas limitaciones deben centrarse más en los procedimientos, de tal manera que se adoptarán aquellos que sean más adecuados a la edad del sujeto.

El ordenamiento jurídico, y esta Ley en particular, van reflejando progresivamente una concepción de las personas menores de edad como sujetos activos, participativos y creativos, con capacidad de modificar su propio medio personal y social; de participar en la búsqueda y satisfacción de sus necesidades y en la satisfacción de las necesidades de los demás.

El conocimiento científico actual nos permite concluir que no existe una diferencia tajante entre las necesidades de 
protección y las necesidades relacionadas con la autonomía del sujeto, sino que la mejor forma de garantizar social y jurídicamente la protección a la infancia es promover su autonomía como sujetos. De esta manera podrán ir construyendo progresivamente una percepción de control acerca de su situación personal y de su proyección de futuro. Este es el punto crítico de todos los sistemas de protección a la infancia en la actualidad. Y, por lo tanto, es el reto para todos los ordenamientos jurídicos y los dispositivos de promoción y protección de las personas menores de edad. Esta es la concepción del sujeto sobre la que descansa la presente Ley: las necesidades de los menores como eje de sus derechos y de su protección".

Se observa claramente cuál es el objetivo de la ley en su Exposición de Motivos, el cual se ve reforzado en el propio articulado, donde resulta de especial interés lo establecido en el art. 2.2 al señalar que las limitaciones a la capacidad de obrar del menor se aplicarán con carácter restrictivo. No es lugar para hacer un análisis en profundidad sobre esta cuestión, pero es preciso señalarlo porque tendremos que volver a ello en alguna ocasión al tratar el funcionamiento de la capacidad de los menores en el ámbito sanitario.
El problema que surge trae causa de la desigualdad que existe en el periodo que comprende esa minoría de edad respecto de las condiciones de autonomía, dependencia o independencia en el desarrollo y evolución del menor, siendo disparejas a medida que el menor va creciendo.

El problema surge ya que las condiciones de capacidad, autonomía, independencia, etc., del menor de edad no son iguales en toda la etapa que dura la minoría. Como se ha leído en las líneas transcritas de la Exposición de Motivos, lo normal es que se vaya produciendo una adquisición paulatina de autonomía, por lo que ese tramo de tiempo que ocupa la minoría de edad se podría separar en varias fases o etapas.

Una primera etapa podría delimitarse desde el nacimiento hasta más o menos los 12 años de edad. En ella, el ser humano es dependiente, dependencia que en el momento del nacimiento es total y que va disminuyendo a medida que va creciendo. En este periodo de dependencia casi absoluta, son los progenitores quienes guardan y cuidan de los menores y los que toman decisiones acerca de todos los aspectos de la vida, educativos, de valores $\mathrm{y}$, cómo no, sanitarios, todo ello en el ejercicio de la patria potestad, cuyo contenido es cuidar y velar por los hijos. 
Una segunda etapa, que se iniciaría a partir de los 12-13 años y que termina claramente a los 16 , en la que el menor va queriendo manifestar su opinión y que se le tenga en cuenta; su autonomía va creciendo y quiere hacerla valer, sobre todo en las cuestiones cotidianas, aunque por supuesto sigue dependiendo de los padres. Comienza una etapa difícil, mediatizada por los amigos y por las modas, que son cambiantes. En el ámbito de la salud, generalmente son los padres los que van a tomar las decisiones, sobre todo cuando se trata de cuestiones importantes. El problema que puede plantearse en esta etapa viene marcado por cuestiones menores, pero que en algunos casos tienen consecuencias negativas.

La tercera etapa que cierra la fase de la minoría de edad es clara y con unos límites muy precisos para ciertos aspectos, en donde la autonomía se asemeja a la de la mayoría de edad pero bajo la guarda y custodia de los padres. La regulación en el ámbito sanitario es diferente a la del menor de 16 años, pues al mayor de esta edad se le considera totalmente capaz de tomar decisiones relacionadas con su salud.

La legislación llega a ser confusa y variada, lo que ocasiona un sinfín de problemas de acoplamiento cuando surgen intereses contrapuestos o diferentes entre padres e hijos. En el ámbito civil, estos problemas se solucionan acudiendo al juez para que se pronuncie sobre lo que es más conveniente; ello también puede ocurrir en el ámbito sanitario, con el inconveniente de la demora en las resoluciones.

\section{El consentimiento informado}

de los menores

La aproximación hecha sobre la capacidad del menor de forma general es necesaria para abordar el tema del consentimiento informado cuando el paciente es un menor.

\section{Planteamiento}

En la actualidad, cuando se habla de consentimiento informado $(\mathrm{Cl})$ se vincula inmediatamente con la Ley 41/2002, de 14 de noviembre, reguladora de la autonomía del paciente y de derechos y obligaciones en materia de información y documentación clínica ${ }^{d}$. Es cierto que su promulgación supuso una regulación más completa en materia de derechos y obligaciones del paciente, que ya estaban regulados en la Ley General de Sani$\mathrm{dad}^{\mathrm{e}}$, aunque llegó un poco tarde, pues muchas comunidades autónomas ya ha-

\footnotetext{
${ }_{\text {BOE n. }}^{\circ} 274$, de 15 de noviembre.

e Artículo 10.
} 
bían legislado al respecto. No procede analizar determinadas cuestiones de orden civil relacionadas con la competencia en determinadas materias, como es la regulación de la capacidad de las personas en el territorio nacional; sin embargo, sí me gustaría señalar que la Ley 41/2002 es una ley básica, lo que significa que las comunidades autónomas han de respetar sus principios básicos.

La ley desarrolla el Convenio de Oviedo relativo a los derechos humanos y la biomedicina, ratificado por España y que entró en vigor en nuestro ordenamiento en enero de 2000.

También hemos de tener en cuenta, al estudiar el $\mathrm{Cl}$, que en la Ley 41/2002 no se hace un estudio pormenorizado por especialidades o actos médicos para los que es preciso la emisión del mismo; solo en aquellos actos que se consideran más delicados se hace una remisión a la ley en general en materia de capacidad y en el caso de que exista una regulación concreta del tema se reenvía a lo preceptuado en ella; sirvan de ejemplo los trasplantes de órganos o los ensayos clínicos. La reciente promulgación de la Ley Orgánica 2/2010, de 3 de marzo, de salud sexual y reproductiva y de la interrupción voluntaria del embarazo, ha modificado en algún aspecto lo establecido como excepciones en el art. 9.4 de la Ley 41/2002.
Además, es preciso apuntar con carácter previo la importancia que tienen determinados preceptos de la Ley 1/1996 de protección jurídica del menor, de la que hemos extraído parte de su Exposición de Motivos, pero que hemos dejado para este momento señalar parte de su contenido relacionado de forma directa con el consentimiento.

Hemos señalado que esta ley pone de manifiesto la adquisición gradual de la capacidad en aras de otorgar autonomía al menor y respetar su dignidad y sus derechos fundamentales. El capítulo II de la ley dedica siete artículos a establecer y reiterar los derechos fundamentales consagrados en nuestra Constitución, poniendo un énfasis especial al hecho de que los menores también gozan de ellos, cuestión que en ningún momento se ha puesto en duda desde la entrada en vigor del texto constitucional. Pero, claro, no debemos olvidar que la ley indica expresamente que el menor tiene derecho a la libertad ideológica y religiosa (punto importante en conexión con algunos temas concretos sanitarios), a la intimidad y a la información, entre otros, lo que significa que tiene derecho a ser informado y que tiene derecho a prestar libremente una opinión y, me atrevería a decir, emitir un consentimiento. Sobre todo si a ello 
le unimos lo establecido en el párrafo 2 del art. 2, al que hacíamos referencia en líneas anteriores y que señala que las limitaciones a la capacidad de obrar se aplicarán con carácter restrictivo.

\section{Recepción de la información y consentimiento informado}

Es inevitable poner en conexión la emisión del consentimiento con la información previa que se debe recibir con anterioridad a cualquier actuación clínica y que se deriva de su propio nombre, "consentimiento informado". De ello se extrae que el paciente, antes de prestar el consentimiento, debe haber sido informado sobre la actuación concreta que se le vaya a practicar.

La Ley 41/2002 se ocupa de este punto concreto en el art. 5, aunque lo hace confusamente -ya explicaremos por qué-. El párrafo primero establece que "el titular del derecho a la información es el paciente".

La afirmación es precisa y clara, la persona que debe ser informada es el paciente, no se especifica si todos los pacientes o solo algunos, atendiendo a su entendimiento o a su juicio. La interpretación que parece más correcta es la de no hacer distinciones por ninguna razón. Es más, algunas leyes autonómicas posteriores sí han hecho aclaraciones en relación con la edad; por citar un ejemplo, la Ley $3 / 2005$ de 8 de julio de asistencia sanitaria de la Comunidad Extremeña ${ }^{f}$, al concretar quiénes deber ser los titulares del derecho a la información asistencial, especifica que los menores de edad serán titulares del derecho a la información cuando estén emancipados o tengan 16 años cumplidos, y termina diciendo que, en otro caso, es decir, cuando no estén ni emancipados y sean menores de 16 años, se les dará información adaptada a su grado de madurez (art. 5.2).

Advertimos cómo la ley extremeña es más precisa que la estatal en este punto concreto, pues deja claro quién debe ser el titular de la información. Sin embargo, a este mismo resultado se llega si conectamos lo establecido en el art. 5.1 de la Ley 41/2002 con el mandato que hace el art. 5, apartado primero, de la Ley $1 / 996$, cuando habla del derecho a la información de los menores en general preceptuando que "los menores tienen derecho a buscar, recibir y utilizar la información adecuada a su desarrollo", esto es, que al menor se le debe de informar siempre que se considere que entiende aquello de lo que se le está informando. Por qué llegamos a esta con-

\footnotetext{
${ }^{f}$ DO Extremadura, de 16 de julio de 2005, n. ${ }^{\circ} 82$.
} 
clusión es fácil de argumentar. Si hacemos un análisis de lo establecido en el Código Civil sobre las actuaciones que pueden llevar a cabo los menores, y lo conectamos con la Ley 1/1996, además de lo que dice la propia de ley de autonomía del paciente en materia de consentimiento y el párrafo segundo del propio art. 5, la conclusión a la que se llega es la que acabamos de mencionar. ¿Qué es lo que dice el párrafo 2 del art. 5?: "El paciente será informado, incluso en caso de incapacidad, de modo adecuado a sus posibilidades de comprensión, cumpliendo con el deber de informar también a su representante legal".

La redacción del párrafo no tiene desperdicio. De una primera lectura, parece desprenderse que cuando un paciente padece una incapacidad, se presume que psíquica porque una incapacidad física no impide entender una información, aquel será informado de manera que llegue a entenderlo. Se obliga también a informar al representante legal. Este último dato nos lleva a pensar que se está haciendo referencia a una persona incapacitada legalmente y a la que se le ha nombrado un tutor, que será informado también ante cualquier actuación médica.

¿Podemos considerar que también se está refiriendo al menor de edad que no es un incapacitado pero que carece de la plena capacidad de obrar y por ello tienen que actuar en su representación sus padres o tutores? Se podría responder afirmativamente; sin embargo, eso se alejaría de la regulación que hace el art. 9 del consentimiento por representación, donde sí se diferencia al menor de edad de la persona incapacitada legalmente y que tiene asignado un tutor.

Se puede interpretar que la ley, en su primer párrafo, ha sido clara al afirmar que se deberá informar al paciente, incluyendo en ella a todos los pacientes, y matizando en el párrafo segundo la situación especial de los incapacitados, o bien que simplemente se ha olvidado de la situación del menor. Me inclino por esta última opción como la más aproximada a la realidad, porque de otro modo habría hecho indicaciones especiales atendiendo a la edad del menor. Resultaría paradójico que el pediatra tuviese que informar al bebé de nueve meses o al niño de seis años del reconocimiento que le va a hacer o de los efectos favorables y los posibles efectos secundarios que le va a ocasionar una vacuna; sin embargo, sí es razonable que se pueda informar a un adolescente entre 12 y 16 años, con independencia que haya que informar también a los padres.

Sin entrar a valorar qué tipo de información ha de trasmitirse al paciente, lo 
que sí me parece necesario resaltar es que la falta de información en una actuación médica ha llevado en muchos supuestos a incurrir en responsabilidad al médico o equipo médico que no la ha facilitado o que no puede probar que sí se ha informado al paciente, al no exigir la ley en todos los casos que la información sea escrita. Como ejemplo de ello, citamos dos sentencias del Tribunal Supremo, la primera de septiembre de 2005, en la que la información es verbal pero hay constancia de haberla ofrecido en la historia clínica:

"El motivo se desestima puesto de acuerdo con reiterada doctrina de esta Sala la exigencia de la constancia escrita de la información tiene, para casos como el que se enjuicia, mero valor ad probationem y puede ofrecerse en forma verbal, en función de las circunstancias del caso (SSTS 2 de noviembre 2000;), habiendo afirmado la sentencia [...] que «al menos debe quedar constancia de la misma en la historia clínica del paciente y documentación hospitalaria que le afecte», como exige la Ley de 24 de noviembre de 2002, reguladora de la autonomía del paciente y de derechos y obligaciones en materia de información y documentación clínica, que constituye el marco normativo actual; doctrina, por tanto, que no anula la va- lidez del consentimiento en la información no realizada por escrito, en la forma que previenen los números 5 y 6 del art. 10 de la Ley General de Sanidad vigente en el momento de los hechos, pero que exige que sea el médico quién pruebe que proporcionó al paciente todas aquellas circunstancias relacionadas con la intervención mientras este se halle bajo su cuidado, incluyendo diagnóstico, pronóstico y alternativas terapéuticas, con sus riesgos y beneficios, como corolario lógico de que se trata de hechos que fácilmente pueden ser probados por él, y que integran, además, una de sus obligaciones fundamentales en orden a determinar la suficiencia o insuficiencia de la información y consiguiente formalización del consentimiento o conformidad a la intervención [...], y que hoy se resuelve a tenor de las reglas sobre facilidad probatoria contenida en el art. 217.6 de la nueva Ley de Enjuiciamiento Civil, que recoge estos criterios jurisprudenciales".

La segunda sentencia es de 29 de mayo de 2003, donde el Tribunal Supremo evalúa cuando la información se facilita a través de impresos tipo que son generales y no valoran la situación especial de cada paciente considerando que no contiene una información completa al señalar: 
“[...] que no se proporcionó al paciente la información adecuada al tratarse de documentos tipo en los que no aparece particularizado su historial, y tal afirmación supone la concreción de un resultado probatorio que no ha sido cuestionado en debida forma. También es correcta la valoración jurídica que se ha dado a estos hechos en cuanto suponen una clara y evidente infracción del deber de información del médico en el tratamiento a que fue sometido $[. .$.$] , ya que dice la senten-$ cia, la aparente sencillez de la misma no podía hacer prever complicaciones tan importantes como las que sucedieron, ni el dato de si los facultativos habían tenido en cuenta el historial médico del mismo. Se trata de simples y escuetos formularios, más próximos a un mero acto administrativo, que médico, que fueron firmados el mismo día de la intervención".

La lectura de estos extractos, aunque no estén referidos especialmente a menores, nos pone de relieve la importancia que tiene la correcta y completa información a efectos de exoneración de responsabilidad. Siendo el propio Tribunal Supremo más exigente en cuanto a la información que se debe dar en una actuación de medicina "satisfactiva" que en la medicina curativa.

¿Qué entiende la ley por consentimiento informado? "La conformidad libre, voluntaria y consciente de un paciente, manifestada en el pleno uso de sus facultades después de recibir la información adecuada, para que tenga lugar una actuación que afecta a su salud".

Es imprescindible que se preste el consentimiento después de haber recibido la información necesaria sobre la actuación médica que se le va a realizar y que afecta a algo tan importante como es la salud, íntimamente ligada al derecho a la vida. El consentimiento es un derecho del paciente y un deber del médico recabarlo, porque si la falta de la información básica al paciente de una actuación médica lleva aparejada la responsabilidad médica, la falta de consentimiento también lleva a incurrir al médico en dicha responsabilidad.

El art. 8 de la Ley 41/2002 de autonomía de paciente nos indica que toda actuación en el ámbito de la salud de un paciente necesita el consentimiento libre y voluntario del afectado...; es decir, en principio, el afectado es el que tiene que prestar el consentimiento. A diferencia de lo que ocurre con el derecho a la información, la ley detalla y concreta determinadas cuestiones relacionadas con los pacientes menores de edad. Así el apartado 3 del art. 9 establece: 
"Se otorgará el consentimiento por representación en los siguientes supuestos:

a) Cuando el paciente no sea capaz de tomar decisiones, a criterio del médico responsable de la asistencia, o su estado físico o psíquico no le permita hacerse cargo de la situación. Si el paciente carece de representante legal, el consentimiento lo prestarán las personas vinculadas a él por razones familiares o de hecho.

b) Cuando el paciente esté incapacitado legalmente.

c) Cuando el paciente menor de edad no sea capaz intelectual ni emocionalmente de comprender el alcance de la intervención. En este caso, el consentimiento lo dará el representante legal del menor después de haber escuchado su opinión si tiene 12 años cumplidos. Cuando se trate de menores no incapaces ni incapacitados, pero emancipados o con 16 años cumplidos, no cabe prestar el consentimiento por representación. Sin embargo, en caso de actuación de grave riesgo, según criterio del facultativo, los padres serán informados y su opinión será tenida en cuenta para la toma de la decisión correspondiente."

De la lectura completa de este párrafo se observa que sí se ha hecho referencia a los menores y que se pueden encuadrar en tres supuestos diferentes: que sea un menor mayor de 16 años; que sea un menor entre 12 y 16 años; o que sea un menor de 12 años.

\section{Menor mayor de 16 años}

Siguiendo el tenor literal de la ley, no hay problema en cuanto al menor que ya ha cumplido 16 años̊. Aquí no se cuestiona si el menor tiene o no capacidad para otorgar el consentimiento, el legislador ha optado por presumir que a la edad de 16 años sí se tiene capacidad para poder decidir y consentir sobre cualquier acto médico. Recordemos que el art. 6 del Convenio de Oviedo no establece esa línea divisoria atendiendo a la edad, sino que parece que tiene más en cuenta la capacidad natural del menor que tiene que prestar el consentimiento ${ }^{\mathrm{h}}$.

A pesar de esta capacidad que se le otorga al menor mayor de 16 años, se establecen una serie de excepciones, con distinto planteamiento:

- En primer lugar, continúa el apartado 3c) del precepto que, en el supuesto de que haya una actua-

$\mathrm{g}$ La referencia a los emancipados no tiene mucho sentido, pues la emancipación solo puede concederse a partir de los 16 años. Habría bastado con esa referencia.

$\mathrm{h}$ En este mismo sentido se manifestaron las leyes autonómicas, incluso aquellas que son anteriores a la ley estatal. 
ción de grave riesgo, según el facultativo, los padres serán informados y se tendrá en cuenta su opinión. ¿Y si la opinión de los padres es contraria a la del adolescente?, ¿a qué deberá atenerse el médico? La casuística puede dar lugar a innumerables escenarios, pero, a no ser que el paciente mayor de 16 años se encuentre en una situación extrema, de no poder ser informado o de no poder prestar el consentimiento, las consecuencias de una actuación médica decidida por los padres y por el facultativo puede generar responsabilidades para todosi.

- El resto de las excepciones vienen contempladas en el apartado 4 del citado artículo: la práctica de ensayos clínicos y la práctica de técnicas de reproducción humana asistida. En estos supuestos la ley se remite a lo establecido con carácter general sobre la mayoría de edad y por las disposiciones especiales de aplicación. Sin olvidar, aunque la ley

\footnotetext{
¡ Además, ese supuesto concreto ya lo prevé el art. 9.3 a) que dice "3. Se otorgará el consentimiento por representación en los siguientes supuestos: a) Cuando el paciente no sea capaz de tomar decisiones, a criterio del médico responsable de la asistencia, o su estado físico o psíquico no le permita hacerse cargo de su situación".
}

no lo menciona expresamente, que los trasplantes de órganos también tienen una regulación específica que afecta de manera especial a la capacidad para el otorgamiento del consentimiento. Sobre este tema, resulta interesante un caso que saltó a la prensa por sus caracteres específicos. Es interesante la lectura del Auto 785/07 de 18 de octubre de 2007 del Juzgado de Primera Instancia n. ${ }^{\circ} 17$ de Sevilla, en el que se autoriza a la menor para donar parte de su hígado a su propia hija.

Los hechos causa del mismo son los siguientes: la madre de una joven de 17 años, en nombre propio y como representante legal de su hija, promovió un expediente de jurisdicción voluntaria, para obtener autorización para que la joven pudiera donar parte de su hígado a su hija de escasos meses de edad. La pequeñai sufre una malformación hepática congénita y necesita, según los médicos especialistas, un trasplante para sobrevivir. Se exploró a la madre del bebe, que era menor, y tanto el informe del mé-

j La pequeña, según los medios de comunicación, ha sido intervenida con éxito, realizándose un trasplante de hígado de un donante fallecido. 
dico forense como el del Ministerio Fiscal fueron favorables sobre la capacidad de entender y conocer de la misma en relación con el acto médico al que iba a someterse. Los fundamentos jurídicos del Auto para una mejor comprensión del caso son recogidos textualmente:

“Primero. La Ley 30/1979, de 27 de octubre, sobre extracción y trasplante de órganos, en su artículo cuarto, establece:

"La obtención de órganos procedentes de un donante vivo para su ulterior injerto o implantación en otra persona podrá realizarse si se cumplen los siguientes requisitos:

Que el donante sea mayor de edad. Que el donante goce de plenas facultades mentales y haya sido previamente informado de las consecuencias de su decisión. Esta información se refería a las consecuencias previsibles de orden somático, psíquico y psicológico, a las eventuales repercusiones que la donación pueda tener sobre su vida personal, familiar y profesional así como a los beneficios que con el trasplante se espera haya de conseguir el receptor.

Que el donante otorgue su consentimiento de forma expresa, li- bre y consciente, debiendo manifestarlo [...]. A los efectos establecidos en esta Ley, no podrá obtenerse ningún tipo de órganos de personas que, por deficiencias psíquicas o enfermedad mental o por cualquier otra causa, no puedan otorgar su consentimiento expreso, libre y consciente [...]».

De similar forma, el RD 2070/ 1999, de 30 de diciembre, (por el que se regulan las actividades de obtención y utilización clínica de órganos humanos y la coordinación territorial en materia de donación y trasplante de órganos y tejidos), en su art. 9, establece las condiciones y requisitos para el donante vivo de órganos:

«1. La extracción de órganos procedentes de donantes vivos para su ulterior trasplante en otra persona podrá realizarse si se cumplen las siguientes condiciones y requisitos:

a) El donante debe ser mayor de edad, gozar de plenas facultades mentales y de un estado de salud adecuado».

Segundo: El Código Civil en su art. 271 no establece la necesidad de que el tutor precise de autorización judicial para autorizar una donación 
de órganos. La Ley 14/1986, de 25 de abril, General de Sanidad, en su art. 10, permite que el tutor preste el consentimiento a la intervención quirúrgica cuando no esté capacitado para ello, en cuyo caso corresponderá a las personas allegadas al incapacitado.

No obstante el silencio normativo, no puede estimarse que para el supuesto de donación de órganos baste el consentimiento del tutor, considerando que, por analogía a los supuestos de esterilización del menor, deberá ser autorizada por el Juez supliendo la falta de capacidad del mismo.

Es necesario, por tanto, acudir al proceso judicial, recabar el informe de especialistas, oír en su caso a la incapaz o menor, todo ello con la intervención del Ministerio Fiscal.

El Tribunal Constitucional establece «La intervención judicial», como inexcusable para que pueda otorgarse la autorización en el supuesto análogo de esterilización, constituyendo la principal garantía a la que están subordinados todas las demás exigiendo los siguientes requisitos:

1) Solicitud por parte de quienes ostenten la representación legal de la persona incapaz ante el Juez del domicilio del incapaz.

2) Exploración judicial de la persona incapaz.

3) Oír a especialistas.

4) Intervención del Ministerio Fiscal. Requisitos que en el presente supuesto se han cumplido, constatando que la menor es plenamente consciente de los riesgos que implica la intervención y que tiene plena capacidad para entender sobre lo actuado; manifestando, con pleno entendimiento y de forma libre $y$ consciente, su deseo de donar a su hija parte de su hígado. Procediendo, en consecuencia, integrar el consentimiento de la menor.

Vistos los artículos citados y demás de general y pertinente aplicación, acuerdo: Parte dispositiva DEBO AUTORIZAR Y AUTORIZO ........ a la donación de hígado solicitada para su hija ......, quedando así suplida su falta de capacidad, integrándose el consentimiento de la misma."

Constituye el primer auto que se pronuncia en España sobre un supuesto de trasplante de órganos, en el que

\footnotetext{
k Véase Tejedor Muñoz L, Ruiz Jiménez J. Notas sobre la responsabilidad en torno a las donaciones de órganos cuando el donante es un menor. Rev Critica Derecho. 2008;(705):427-40.
} 
se permite que donante y receptor sean menores; por tanto, no contamos con antecedentes sobre casos similares, sin duda, la problemática y la trascendencia humana y jurídica de esta cuestión ponen de relieve que a veces los propios tribunales, en aras de la equidad, no hacen una aplicación exhaustiva de las normas. La ley es clara; como hemos visto, se exige la mayoría de edad para ser donante vivo. Al final, el auto no se ejecutó porque el bebé recibió un órgano y se le practicó el trasplante.

Respecto de la práctica de las técnicas de reproducción asistida, La Ley 35/ 1988 de 22 de noviembre sobre técnicas de reproducción asistidal establece en el art. 6.1 in fine que la usuaria de las técnicas "Deberá tener 18 años al menos y plena capacidad de obrar", por lo tanto, se podía haber omitido esta excepción, ya que la Ley 41/2002 es de carácter supletorio en relación con la legislación especialm ${ }^{m}$.

En cuanto a los ensayos clínicos, siguiendo la literalidad de la norma, el menor mayor de 16 años no puede otorgar el

\footnotetext{
I BOE n. ${ }^{\circ} 282$, de 24 de diciembre. Se modificó por la Ley 45/2003 (aunque los artículos afectados fueron el 4 y el 11).

${ }^{m}$ Así lo establece la Disposición Adicional Segunda respecto de una serie de supuestos entre los que se encuentra la práctica de estas técnicas.
}

consentimiento, tenemos que remitirnos a lo establecido con carácter general para la capacidad y a la legislación especial allí donde hay regulación. El Convenio de Oviedo establece que para poder llevar a cabo ensayos clínicos en menores ${ }^{n}$, siempre y cuando se cumplan los requisitos establecidos en el propio Convenio, será necesario el consentimiento por escrito del representante del menor, y que no haya un rechazo por el propio menor. Incluso, se considera necesario ponerlo en conocimiento del Ministerio Fiscal, a tenor de lo dispuesto en el Real Decreto 223/2004 de 6 de febrero por el que se regulan los ensayos clínicos con medicamentos ${ }^{\circ}$. Por lo

${ }^{\mathrm{n}}$ Artículo 17, en consonancia con el artículo 6.

- El consentimiento informado se regula en el artículo 7 del Real Decreto, dedicando el apartado 3 al consentimiento cuando el ensayo se va a realizar con un menor:

“3. Cuando el sujeto del ensayo no sea una persona capaz para dar su consentimiento o no esté en condiciones de hacerlo, la decisión deberá adoptarse, teniendo en cuenta lo indicado en este artículo. Si el sujeto del ensayo es menor de edad:

1. Se obtendrá el consentimiento informado previo de los padres o del representante legal del menor; el consentimiento deberá reflejar la presunta voluntad del menor y podrá retirarse en cualquier momento sin perjuicio alguno para él. Cuando el menor tenga 12 o más años, deberá prestar además su consentimiento para participar en el ensayo. 2. El menor recibirá, de personal que cuente con experiencia en el trato con menores, una información sobre el ensayo, los riesgos y los beneficios, adecuada a su capacidad de entendimiento. 3. El investigador aceptará el deseo explícito del menor de negarse a participar en el ensayo o de retirarse en cualquier momento, cuando este sea capaz de formarse una opinión en función de la información recibida. 4. El promotor pondrá en conocimiento del Ministerio Fiscal las autorizaciones de los ensayos clínicos cuya población incluya a menores". 
tanto, observamos que el legislador ha considerado que para estos casos el menor mayor de 16 años no tiene capacidad suficiente para otorgar el consentimiento.

Se presume que hay que tratar de la misma manera al menor emancipado y al menor mayor de 16 años que no está emancipado. En el supuesto de la utilización de técnicas de reproducción asistida, desde luego, pues la propia ley exige la mayoría de edad para poder utilizar las mismas.

Había una tercera excepción en ese apartado 4, la interrupción voluntaria del embarazo. Sin embargo, con la aprobación de la Ley Orgánica 2/2010, de 3 de marzo, de salud sexual y reproductiva y de la interrupción voluntaria del embarazoP (que entró en vigor el 4 de julio de 2010), se ha suprimido esta excepción, siendo de aplicación lo establecido en el apartado 4 del art. 13, que establece que:

"En el caso de las mujeres de 16 y 17 años, el consentimiento para la interrupción voluntaria del embarazo les corresponde exclusivamente a ellas de acuerdo con el régimen general aplicable a las mujeres mayores de edad.

Al menos uno de los representantes legales, padre o madre, personas con pa-

P BOE n. ${ }^{\circ}$ 55, de 4 de marzo de 2010. tria potestad o tutores de las mujeres comprendidas en esas edades deberá ser informado de la decisión de la mujer.

Se prescindirá de esta información cuando la menor alegue fundadamente que esto le provocará un conflicto grave, manifestado en el peligro cierto de violencia intrafamiliar, amenazas, coacciones, malos tratos, o se produzca una situación de desarraigo o desamparo."

De la lectura de este precepto se desprende claramente que la menor mayor de 16 años podrá decidir y consentir sobre la interrupción voluntaria del embarazo, siempre que se den los requisitos señalados en la norma, incluso sin conocimiento de los padres.

Una vez señaladas las excepciones establecidas en la ley, nos preguntamos si están todos los casos posibles en los que se presume que el menor maduro, el adolescente o el emancipado no tienen todavía la suficiente capacidad para consentir sobre algo que afecta a su salud, o debería añadirse alguno más.

Desde mi punto de vista, hay un supuesto que debería figurar como la tercera excepción sobre la necesidad de mayoría de edad para prestar consentimiento, y es el sometimiento a cualquier tipo de cirugía estética, cuando no vaya acompañada de otra dolencia que lo aconseje. No olvidemos que los meno- 
res maduros están obsesionados por la belleza, influenciados por los cánones marcados por la sociedad actual. Sobre este tema, se podría pensar que, teniendo en cuenta el objeto de la prestación, no es necesario para la salud, y se tendría que dar una información más exhaustiva, tal como ha manifestado el Tribunal Supremo en la sentencia de 23 de mayo de 2007 en su fundamento tercero al manifestar que:

"El deber de información en la medicina satisfactiva en la doctrina reiterada por la jurisprudencia de esta Sala y destacada por la parte recurrente debe ser una información objetiva, veraz, completa y asequible, y comprende las posibilidades de fracaso de la intervención, es decir, el pronóstico sobre la probabilidad del resultado, y también cualesquiera secuelas, riesgos, complicaciones o resultados adversos se puedan producir, sean de carácter permanente o temporal, con independencia de su frecuencia".

Está claro que las operaciones de cirugía estética están basadas en un resultado, estaríamos ante una obligación de resultado y no de medios; por ello, parece acertada la idea de exigir un mayor rigor en la información de los resultados adversos que se puedan ocasionar, con mayor cuidado incluso en los menores de edad, ya que las secuelas, no solo fí- sicas sino también psicológicas, pueden afectar considerablemente al menor para el resto de su vida. Andalucía ha tenido la iniciativa de regular expresamente este tema en el Decreto 49/2009 de 3 de marzo de protección de las personas menores de edad que se someten a intervenciones de cirugía estética y de creación del registro de datos sobre intervenciones de cirugía estética realizadas a personas menores de edad en dicha comunidadq. En ella se da especial importancia al derecho a que el menor reciba una información adaptada a su edad y a su desarrollo afectivo y psicológico; también, que conozca los riesgos que conlleva una intervención de estas características. Para ello, entre otros requisitos, se requiere que haya un informe de un profesional tras un examen psicológico, exigiendo además que el informe esté a cargo de un profesional que no tenga vinculación laboral o contractual con el centro o servicio sanitario, o con la persona que va a realizar la intervención de cirugía estética. Hasta aquí, todo parece correcto y encaminado a proteger al menor que decide realizarse una intervención; sin embargo, este informe será valorado por la persona facultativa que vaya a realizar la in-

\footnotetext{
$9_{\text {BOJA n. }}^{\circ}$ 53, de 18 de marzo de 2009.
} 
tervención, y será ella quien determine la pertinencia de la intervención y la idoneidad del menor. A tenor de ello, nos surgen infinidad de interrogantes, teniendo en cuenta que en la mayoría de los supuestos estas intervenciones se hacen en clínicas privadas; lo dejamos así apuntado.

En cuanto al consentimiento, la ley dice que lo otorgará el menor de edad, o sus padres, o representantes legales. No aclara mucho en cuanto a la edad idónea que ha de tener el menor; ¿qué ocurre en caso de conflicto entre padres o representantes y el menor? En fin, hay también un poco de confusión sobre cuándo procede que emitan el consentimiento los padres o tutores y cuándo el propio menor.

\section{Menor entre 12 y 16 años}

Cuando el consentimiento lo tiene que prestar un menor, mayor de 12 años y menor de 16, el tema puede resultar ambiguo. Hemos establecido este margen (entre 12 y 16 años) porque de forma tácita lo está haciendo la propia ley. Como señalábamos en líneas anteriores, se otorgará el consentimiento por representación cuando el menor de edad no sea capaz, intelectual ni emocionalmente, de comprender el alcance de la intervención. En ese supuesto, el consenti- miento lo dará el representante, pero después de haber oído la opinión del menor si tiene 12 años cumplidos.

En primer lugar, habrá que precisar cuándo se considera por el legislador que el menor es capaz, intelectual y emocionalmente, de entender la información que está recibiendo y posteriormente prestar el consentimiento a cualquier actuación médica. Para ello, Sánchez-Caro y Abellán afirman que desde un punto de vista forense los criterios utilizados para evaluar la capacidad civil de un individuo son: el criterio cognitivo y el criterio volitivor.

La siguiente pregunta que hemos de hacernos es ¿quién determina si la capacidad natural del menor está dentro de los parámetros mínimos para entender y querer? Se desprende de la norma que es el médico que le atiende quien lo determina. Quizá debería haberse especificado que ha de ser un especialista que, tras examinar al menor, estime si su capacidad natural le permite tomar

\footnotetext{
${ }^{r}$ Consideran que "el criterio cognitivo supone que en el momento de la ejecución del hecho posea la inteligencia y el discernimiento de sus actos. Y el criterio volitivo, que goce de la libertad de su voluntad, de su libre albedrío; es decir, de la facultad de poder escoger entre los diversos motivos de conducta que se presenten ante su espíritu y de determinar libremente la potencia de su voluntad". En: Sánchez-Caro y Abellán. Derechos y deberes de los pacientes. Ley 41/2002 de 14 de noviembre; 2003, pág. 57.
} 
determinadas decisiones sobre su salud, en la línea que ha comenzado la ley andaluza. Además, la cuestión se presenta compleja cuando la voluntad del menor y la del representante no son coincidentes: ¿cuál prevalece?, ¿variará dependiendo de los supuestos?

Siendo la voluntad de los padres y del menor coincidente, el Tribunal Constitucional se manifestó sobre la capacidad de decisión de un menor de 13 años, testigo de Jehová, en la sentencia 154/2002, que tras la negativa del menor a que le practicasen una transfusión de sangre, alegando sus convicciones religiosas, se produjo el fallecimiento del mismo. En este caso, el Tribunal Constitucional considera que, por encima de todo, está el interés del menor y el derecho a la vidas.

\footnotetext{
${ }^{s}$ Es de especial interés el razonamiento que el Tribunal Constitucional hace de la confrontación entre el derecho a la libertad religiosa y el derecho a la vida del menor:

"Pasemos ahora a considerar la relevancia que, en su caso, pueda tener la oposición manifestada del menor al tratamiento médico prescrito.

En el recurso de amparo se alega precisamente, como ya hemos indicado, el error de la Sentencia impugnada al establecer «la irrelevancia del consentimiento u oposición de un niño menor de 13 años de edad, máxime cuando, como en este caso, está en juego su propia vida».

Es cierto que el Ordenamiento jurídico concede relevancia a determinados actos o situaciones jurídicas del menor de edad. Ello se aprecia en concreto -atendiendo a la normativa que pudiera regular las relaciones entre las personas afectadas por el tema que nos ocupa- tanto en la Compilación del Derecho Civil de Aragón (aplicable en cuanto tuvieran la vecindad civil en dicho territorio foral) como, en su caso, en el Código Civil. Así, los actos relativos a los derechos de la personalidad (entre los que se
}

halla precisamente el de integridad física), de los que queda excluida la facultad de representación legal que tienen los padres en cuanto titulares de la patria potestad, según explícitamente proclama el art. 162.1 del Código civil (precepto sin correlato expreso en la Compilación); tal exclusión, por otra parte, no alcanza al deber de velar y cuidar del menor y sus intereses. También cabe señalar diversos actos conducentes a la creación de efectos jurídicos o a la formalización de determinados actos jurídicos, como son, entre otros, los relativos a la capacidad para contraer matrimonio, para testar, para testificar, para ser oído a fin de otorgar su guarda o custodia a uno de los progenitores. Y asimismo, en el ámbito penal, para la tipificación de determinados delitos.

Ahora bien, el reconocimiento excepcional de la capacidad del menor respecto de determinados actos jurídicos, como los que acaban de ser mencionados, no es de suyo suficiente para, por vía de equiparación, reconocer la eficacia jurídica de un acto -como el ahora contemplado- que, por afectar en sentido negativo a la vida, tiene, como notas esenciales, la de ser definitivo $y$, en consecuencia, irreparable.

De las consideraciones precedentes cabe concluir que, para el examen del supuesto que se plantea, es obligado tener en cuenta diversos extremos. En primer lugar, el hecho de que el menor ejercitó determinados derechos fundamentales de los que era titular: el derecho a la libertad religiosa y el derecho a la integridad física. En segundo lugar, la consideración de que, en todo caso, es prevalente el interés del menor, tutelado por los padres y, en su caso, por los órganos judiciales. En tercer lugar, el valor de la vida, en cuanto bien afectado por la decisión del menor: según hemos declarado, la vida, "en su dimensión objetiva, es 'un valor superior del ordenamiento jurídico constitucional' y 'supuesto ontológico sin el que los restantes derechos no tendrían existencia posible' (STC 53/1985 [RTC 1985, 53])» (STC 120/1990, de 27 de junio [RTC 1990, 120], F. 8). En cuarto lugar, los efectos previsibles de la decisión del menor: tal decisión reviste los caracteres de definitiva e irreparable, en cuanto que conduce, con toda probabilidad, a la pérdida de la vida.

En todo caso, y partiendo también de las consideraciones anteriores, no hay datos suficientes de los que pueda concluirse con certeza -y así lo entienden las Sentencias ahora impugnadas- que el menor fallecido, hijo de los recurrentes en amparo, de 13 años de edad, tuviera la madurez de juicio necesaria para asumir una decisión vital, como la que nos ocupa. Así pues, la decisión del menor no vinculaba a los padres respecto de la decisión que ellos, a los efectos ahora considerados, habían de adoptar. [...] 


\section{Menor de 12 años}

Es el supuesto menos problemático de todos. Aunque si nos atenemos a la normativa general sobre capacidad, el Código Civil no delimita edad concreta como hace la Ley 41/2002, simplemente hace alusión a la madurez.

Para terminar, me gustaría hacer referencia a una serie de cuestiones que,

Sentados los anteriores extremos, debemos establecer si la condición de garantes, atribuida por las Sentencias impugnadas a los recurrentes en amparo, resulta afecta$\mathrm{da}-\mathrm{y}$, en su caso, en qué sentido- por el derecho de estos a la libertad religiosa. Es claro que ello comporta la necesidad de tener en cuenta las singulares circunstancias concurrentes en el caso que nos ocupa, de que ya se hizo mérito.

Una consideración previa es necesaria. Ya se ha indicado (fundamento jurídico segundo) que el Ministerio Fiscal niega que -como cuestión fáctica ya resuelta-deba cuestionarse en amparo la inobservancia por parte de los padres de la posición de garantes de la vida del hijo. Afir$\mathrm{ma}$, al respecto, el Ministerio público que «el concepto de garante aplicado a los actores por la sentencia nace, y por ello pertenece al campo de la legalidad ordinaria, de la subsunción del supuesto fáctico, consistente en la generación y la falta de edad del hijo, en la normativa legal reguladora de la patria potestad», y que "esta subsunción se realiza por el órgano judicial de manera razonada y fundada en derecho, único por determinación legal que puede y debe hacerla». Concluye esta consideración el Ministerio público diciendo que «el Tribunal Supremo estudia esta situación y declara razonada y fundadamente que los recurrentes nunca perdieron el dominio de la situación de garantes, y esta afirmación constituye una cuestión fáctica que, resuelta por el Tribunal en forma legal, carece de dimensión constitucional».

No puede admitirse, en su radicalidad, la tesis expuesta, la cual -en realidad- hace supuesto de la cuestión sometida a debate. Los derechos y obligaciones que surgen en el ámbito de las relaciones humanas -concretados por las normas que estructuran la llamada legalidad ordinaria- son válidos y eficaces en la medida en que su contenido no rebasa el marco constitucional, respetando los límites propios de los derechos fundamentales." aunque no pueden considerarse intervenciones médicas, sí han tenido en alguna ocasión efectos contrarios a la salud $y$, además, han sido objeto de conflicto entre los jóvenes y sus padres; me estoy refiriendo a la práctica de tatuajes, perforación cutánea (piercing) u otros tipos de adorno corporal. Si lo conectamos con la Ley 1/1996 de Protección Jurídica del Menor y con la Ley 41/2002, parece seguro que, a partir de los 16 años, los menores podrán prestar su consentimiento si necesidad de ningún complemento de capacidad; sin embargo, existe una legislación específica para estas actuaciones.

En la Comunidad de Madrid está regulado por el Decreto 35/2005 de 10 de marzo del Consejo de Gobierno por el que se regulan estas prácticas. Con independencia de que se establezcan los requisitos que deben tener los establecimientos que se dediquen a realizar estas prácticas, también dedica algún artículo al tema del consentimiento informado. En concreto el art. 11. 3 establece que "los mayores de edad prestarán consentimiento informado válido de forma autónoma. En relación con los menores de edad e incapaces, se estará a lo dispuesto en el siguiente artículo".

En concreto, el art. 12, dedicado a menores e incapaces, dice así: 
"1. Las prácticas objeto de regulación en el presente Decreto únicamente podrán realizarse a menores e incapaces previa petición de estos, con consentimiento informado y con respeto a su dignidad. La información que deberá serles prestada será adecuada a sus posibilidades de comprensión.

2. El consentimiento informado de los menores no emancipados deberá prestarse por sus representantes legales.

3. El consentimiento informado de los incapaces deberá prestarse por ellos mismos o por sus representantes legales, atendiendo a la extensión y los límites que determine la sentencia de incapacitación."

En primer lugar, se diferencia a los menores emancipados de los no emancipados, por lo que se aleja de lo establecido en la ley de autonomía del paciente, que equipara a los menores de 16 años con los emancipados, por lo que se aumenta la rigidez en este extremo, ya que el menor, aunque tenga 17 años, necesita la autorización de sus padres o representantes legales. Aunque es cierto que esto supone una garantía adicional para los menores, e incluso para las personas que los realizan, va en contra del espíritu de la Ley 1/1996 de protección jurídica del menor.
Además, en el art. 11 se especifica que deberá seguirse el modelo del Anexo III en cuanto a la información que se debe dar y a los requisitos de validez del documento, lo transcribimos a continuación para su conocimiento:

"El documento impreso de consentimiento informado deberá contener, al menos, la siguiente información:

a) Datos identificativos del establecimiento y del aplicador.

b) Datos identificativos y edad del usuario y, en su caso, del representante legal. Se adjuntará fotocopia de DNI o pasaporte.

c) Descripción detallada de la práctica a realizar, así como de los productos y/o materiales que se apliquen o implanten.

d) Los riesgos y complicaciones que se pueden derivar.

e) Los cuidados posteriores a la realización de las mismas.

f) Las condiciones de reversibilidad de la práctica a realizar.

g) La indicación de consultar al médico en caso de que el usuario padezca enfermedades o que se produzcan complicaciones posteriores.

h) Fecha, firma y DNI del usuario o representante legal.

i) La posibilidad de revocar este consentimiento en cualquier momento sin necesidad de expresar motivación alguna. 
j) Leyendas que indiquen el correcto tos que, de hecho son menos numerotratamiento de los datos de carácter sos de lo que cabría esperar, pues en personal, conforme a la normativa es- la mayoría de los casos las relaciones pecífica vigente." familiares priman sobre cualquier otro

El panorama es cuanto menos con- interés y casi siempre se llega a un fuso y no exento de probables conflic- consenso. 